\title{
Experimental and computational analysis (DFT method) of some quinoxalinones and benzoxazinones: spectroscopic investigation (FT- IR, FT-Raman, UV-Vis, NMR)
}

\author{
JELENA PETRONIJEVIĆa,*, NENAD JOKSIMOVIĆ ${ }^{\mathrm{a}}$, ZORICA BUGARČIĆ ${ }^{\mathrm{a}}$, \\ ELVIRA ĐURĐIĆ ${ }^{\mathrm{b}}$ and NENAD JANKOVIĆ ${ }^{\mathrm{a}, *}$ \\ ${ }^{a}$ Department of Chemistry, Faculty of Science, University of Kragujevac, Radoja Domanovića 12, \\ Kragujevac 34000, Serbia \\ ${ }^{b}$ Department of Physics, Faculty of Science, University of Novi Sad, Trg Dositeja Obradovica 4, \\ Novi Sad 21000, Serbia \\ E-mail: jelena.petronijevic@pmf.kg.ac.rs; nenad.jankovic@kg.ac.rs
}

MS received 16 May 2019; revised 15 July 2019; accepted 22 July 2019

\begin{abstract}
The selected quinoxalinones and benzoxazinones derivatives, synthesized in our laboratory earlier, were explored by spectroscopic techniques (UV-Vis, IR, Raman and NMR) and theoretical study (DFT calculations). In order to understand the electronic properties of these compounds, the theoretical UV spectra have been investigated by TDDFT/B3LYP method with $6-311+\mathrm{G}(\mathrm{d}, \mathrm{p})$ basis set in ethanol as a solvent. For all compounds, the absorption of UV radiation with a wavelength around $415 \mathrm{~nm}$ with an oscillator strength $f=0.90$ induces the intramolecular electronic transition $\left(n \rightarrow \pi^{*}\right)$. The frontiers molecular orbitals are calculated, and contributions of the electronic transitions are determined. Also, we did quantum chemical calculations to investigate the corrosion inhibition properties of these molecules. The vibrational analysis was performed at the B3LYP/6-311+G(d,p) level of theory in vacuo. Obtained results are in very good agreement with experimental data. The calculated ${ }^{13} \mathrm{C}$ NMR shifts in all cases are in good-to-excellent agreement. Also, ${ }^{1} \mathrm{H}$ NMR predicted shifts are comparable with experimental results, but there are some deviations (for $\mathrm{N}-\mathrm{H}$ shifts) probably as a consequence of intramolecular interactions.
\end{abstract}

Keywords. Quinoxalinones; 1,4-benzoxazin-2-ones; vibrational analysis; corrosion inhibition; simulated ${ }^{13} \mathrm{C}$ and ${ }^{1} \mathrm{H}$ spectra.

\section{Introduction}

The quinoxaline and benzoxazine derivatives are mainly known for their wide range of pharmacological and biological activities. ${ }^{1-3}$ Their ring moieties are part of the chemical structures of various antibiotics such as echinomycin, levomycin and actinomycin. ${ }^{2}$ Such compounds are also known to be active against transplant tumors. ${ }^{4}$ Also, quinoxaline-based compounds have the ability to inhibit the metal corrosion and they are used in electroluminescent materials., Physicochemical properties of inhibitors (e.g., electron density, geometric factors, molecular volume, etc.,) determine their effectiveness of corrosion, while the process of adsorption depends on the type of metal, the nature of inhibitor, and the electrochemical potential at the metal-solution surface. ${ }^{7}$ Many quinoxaline derivatives have been reported as efficient inhibitors of metal corrosion in acidic medium in the last few years. $^{8-12}$ Nowadays, many scientists and engineers are investigating new synthetic routes for the synthesis of novel corrosion inhibitors with even better properties. There are numerous methods available for the synthesis of quinoxaline and benzoxazine derivatives. In recent times, several green methodologies that include recyclable catalysts, microwave-assisted synthesis and reactions in aqueous medium are presented. ${ }^{13,14}$ Bearing in mind the biological, structural, and industrial importance of quinoxaline- and benzoxazine-based compounds, we used these previously

*For correspondence

Electronic supplementary material: The online version of this article (https://doi.org/10.1007/s12039-019-1681-y) contains supplementary material, which is available to authorized users. 
synthesized compounds for DFT calculations. ${ }^{13}$ The studied quinoxaline and benzoxazine derivatives namely 3,4-dihydro-3-[2-oxo-2-(4-methoxyphenyl) ethylidene]-2(1H)-quinoxalinone (1), 3,4-dihydro-3(5-methyl-2-oxo-hex-5-enylidene)-2(1H)-quinoxalinone (2), 3,4-dihydro-3-[2-oxo-2-(3-nitrophenyl)ethylidene] -2(1H)-quinoxalinone (3) and 3,4-dihydro-3-[2-oxo-2(3-N-acetylphenyl)ethylidene]-1,4-benzoxazin-2-one (4) are presented in Figure 1. In this study, the equilibrium conformation of selected compounds was predicted theoretically using B3LYP/6-311+G(d,p) level of theory. Obtained optimized structural parameters are compared with crystal structure data of similar molecular structure. In order to investigate the corrosion inhibition properties of these molecules we calculated quantum chemical parameters. The complete assignments were performed on the recorded FT-IR spectrum based on theoretically predicted wavenumbers and their TED. The calculated vibrational frequencies are scaled to compensate for the approximate treatment of electron correlation, for basis set deficiencies and for the anharmonicity. ${ }^{15,16}$ The electronic transitions and isotropic chemical shifts were analyzed via $\mathrm{UV}-\mathrm{Vis}$ and ${ }^{1} \mathrm{H}$ and ${ }^{13} \mathrm{C} \mathrm{NMR}$ techniques. We have carried out DFT calculations with the combined Becke's three-parameter exchange functional in combination with the Lee, Yang and Parr correlation functional (B3LYP). ${ }^{17-19}$ Computational techniques can facilitate the solution of the problems confronted in experimental chemistry.

\section{Experimental and theoretical calculations}

\subsection{Experimental}

The synthesis of the selected compounds was previously reported by our investigation group. ${ }^{13}$ All solvents were purchased from Sigma Aldrich and used without purification. UV spectra $\left(\mathrm{c}=1.0 \times 10^{-4} \mathrm{~mol} \mathrm{dm}^{-3}\right.$, path length $1 \mathrm{~cm}$ ) were measured in ethanol as solvent, in the wavelength range of 200-600 nm using a Perkin Elmer Lambda 35 double-beam spectrophotometer at $25{ }^{\circ} \mathrm{C}$. The IR spectra were recorded via Perkin-Elmer Spectrum One FT-IR spectrometer on a $\mathrm{KBr}$ pellet in the range of $400-4000 \mathrm{~cm}^{-1}$. Raman spectra were collected using Thermo Fisher Scientific DXR Raman Microscope at $25{ }^{\circ} \mathrm{C}$. This device uses DPSS (Diode Pumped Solid State) lasers with wavelength $\lambda=780 \mathrm{~nm}$. The laser used for the excitation is coupled with the optical Olympus microscope and objective with 10 magnification, which focuses the laser beam onto the sample. Through the same microscope objective and pinhole aperture with diameter of $50 \mu \mathrm{m}$, Raman backscattered data was collected with CCD camera as a detector. The recorded wavenumbers are expected to be accurate within $\pm 4 \mathrm{~cm}^{-1}$ in the range of $50-3395 \mathrm{~cm}^{-1}$. OMNIC software was used for collecting and analyzing the obtained Raman spectra of the samples. The NMR spectra
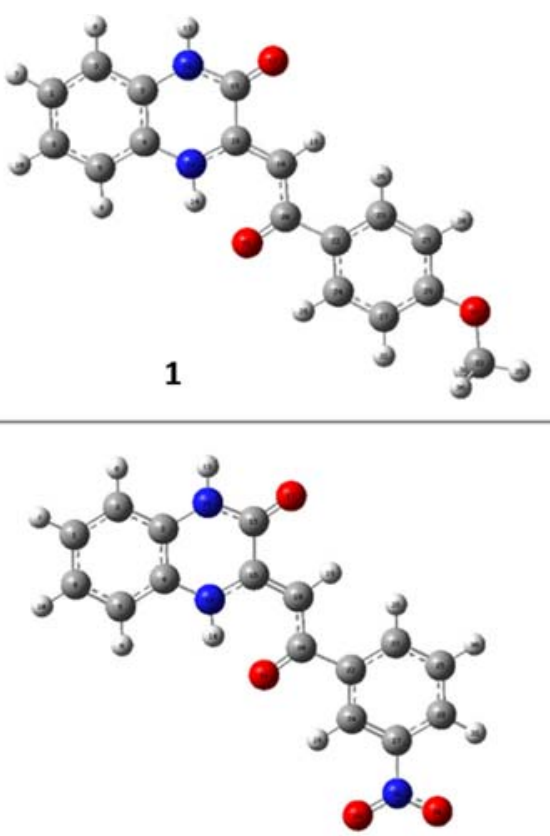

3
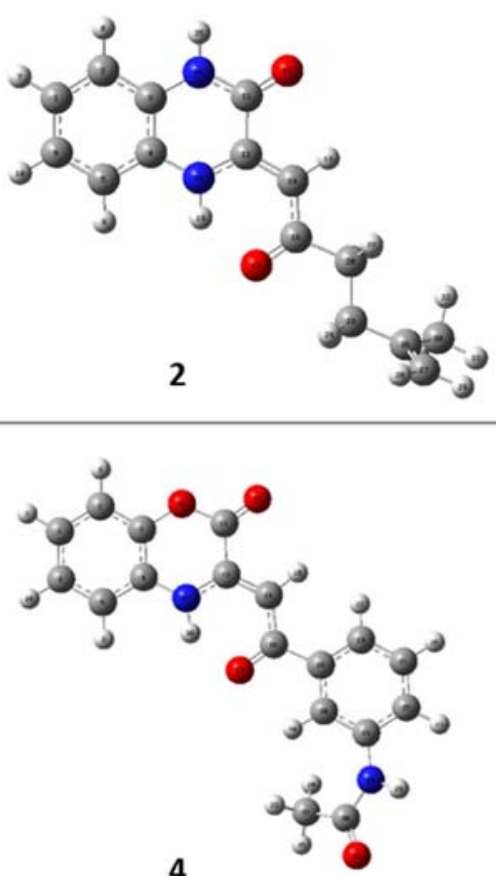

4

Figure 1. Optimized structures of investigated compounds. 
of the evaluated compounds have been performed in DMSO- $\mathrm{d}_{6}$ with TMS as the internal standard on a Varian Gemini $200 \mathrm{MHz}$ NMR spectrometer $\left({ }^{1} \mathrm{H}\right.$ at 200 and ${ }^{13} \mathrm{C}$ at $50 \mathrm{MHz}$ ). Physical properties of compound 1: orange powder, M.p. $=241{ }^{\circ} \mathrm{C}$; compound 2: orange powder, M.p. $>300{ }^{\circ} \mathrm{C}$; compound 3: orange powder, M.p. $>$ $300{ }^{\circ} \mathrm{C}$; compound 4: yellow powder, M.p. $=235^{\circ} \mathrm{C}$.

\subsection{Computational details}

All optimizations of geometries were performed using the density functional theory (DFT) at the B3LYP functional (Becke's Three Parameter Hybrid Functional using the LeeYang-Parr correlation functional). ${ }^{18,19}$ Calculations were performed using the $6-311+\mathrm{G}(\mathrm{d}, \mathrm{p})^{20}$ basis set using GAUSSIAN 09 package. $^{21}$ In this work, the B3LYP/6$311+\mathrm{G}(\mathrm{d}, \mathrm{p})$ theoretical model was used to obtain the ground state geometries of selected quinoxalinones and oxazinones in vacuo. Frequency calculations showed that there were no imaginary frequencies, which indicates that the stationary points correspond to the equilibrium geometries. The calculated molecular geometry was used as an input structure for further calculations (UV-Vis, IR, Raman, ${ }^{1} \mathrm{H}$ and ${ }^{13} \mathrm{C}$ NMR spectra). For better understanding of electronic properties, the theoretical UV spectra have been calculated by TDDFT/B3LYP method with $6-311+\mathrm{G}(\mathrm{d}, \mathrm{p})$ basis set in ethanol as a solvent. The optimized molecular structures in vacuo are used for the computation of vibrational frequencies and Raman activities. Calculated vibrational frequencies were scaled down using a single scaling factor of $0.9679 .^{22}$ Quantum chemical properties are also investigated in order to determine corrosion inhibition of selected compounds. The ${ }^{1} \mathrm{H}$ and ${ }^{13} \mathrm{C}$ NMR isotropic chemical shifts were calculated using the GIAO method with DMSO as a solvent. ${ }^{23}$ The ${ }^{1} \mathrm{H}$ and ${ }^{13} \mathrm{C}$ NMR chemical shifts of TMS in DMSO were also calculated at the B3LYP/ $6-311+G(d, p)$ level of theory and they equal 32.0121 and $184.5363 \mathrm{ppm}$, respectively. Calculated chemical shifts were scaled using scaling factors of $0.9409\left({ }^{13} \mathrm{C}\right)$ and $1.1119\left({ }^{1} \mathrm{H}\right)$, that are obtained using the least squares method.

\section{Results and Discussion}

\subsection{Molecular geometry}

The optimized structural parameters of the molecule 2 are obtained from B3LYP/6-311+G(d,p) level of theory, and listed in Table 1 . The crystal structure of compound $\mathbf{2}$ is not obtained so we compared the optimized structure with a similar system for which the X-ray data have been obtained, for example, 3,4dihydro-3-(2-oxo-hex-5-enylidene)-1,4-benzoxazin-2one. ${ }^{13}$ Heterocycle ring of compound 2 , that is part of two tethered six-membered rings is almost ideally planar that is confirmed for the crystal structure of similar compound 3,4-dihydro-3-(2-oxo-hex-5-enylidene)-1,4-benzoxazin-2-one. Calculated dihedral angle of $0.12^{\circ}$ between $\mathrm{N}(18)-\mathrm{C}(12)-\mathrm{C}(14)-\mathrm{C}(16)$ and dihedral angle of $176,71^{\circ}$ between $\mathrm{C}(14)-\mathrm{C}(16)-\mathrm{C}(20)$ $\mathrm{C}(23)$ indicate that all atoms in the molecule (except for the terminal C26-C27-C30 fragment) are part of a large planar system.

Planar conformation of the almost whole system is probably stabilized by a relatively strong intramolecular hydrogen bond, such as $\mathrm{N}-\mathrm{H} \cdots \mathrm{O}[\mathrm{H} \cdots \mathrm{O}=2.01 \AA$, $\left.\mathrm{N}-\mathrm{H} \cdots \mathrm{O}=134^{\circ}\right] .{ }^{13}$ As can be seen in Table 1 , theoretical configurations do not match completely with the XRD values. The reason for the deviation is that these calculations refer to the equilibrium structure of an isolated molecule in the gas phase and the experimental results belong to another similar molecule in the condensed phase.

\subsection{Vibrational analysis}

In order to obtain the spectroscopic data for selected compounds we computed harmonic vibrational frequencies using the B3LYP/6-311+G(d,p) level of theory in vacuo and the results are listed in Table 2. There are some disagreements between calculated and experimental vibrational wavenumbers because calculations were made in vacuo, but experiments were performed for solid-state. The calculated vibrational frequencies were scaled-down with a scaling factor of 0.9679. Based on the calculated normal mode frequencies, the theoretical IR and Raman spectra were convoluted, and it was compared with the experimental FT-IR spectra in Figures 2 and 3 for compounds $1,2,3$ and 4 . The calculated vibrational wavenumbers $\left(v_{\text {calc }}\right)$ correlate very well with the experimental data $\left(v_{\text {exp }}\right)$ with the correlation equation $v_{\text {calc }}=1.0318 \cdot v_{\exp }-71.069$ and the correlation coefficient $\left(\mathrm{r}^{2}\right)$ of 0.9993 for compound 1 . The assignments of selected modes with TED contributions are given in Table 2. The various functional group analysis was discussed as below.

3.2a $C-H$ vibrations: The $\mathrm{C}-\mathrm{H}$ stretching vibrations of aromatic and aliphatic compounds occur in the ranges of 3100-3000 and 3000-2840 $\mathrm{cm}^{-1}$, respectively. ${ }^{23}$ The calculated aromatic $\mathrm{C}-\mathrm{H}$ stretching vibrations were found to be at 3097, 3085, and $3070 \mathrm{~cm}^{-1}$ for the $\mathrm{C}-\mathrm{H}$ bonds of the aromatic ring bearing quinoxalinone scaffold in all cases, and at 3107,3094 and $3080 \mathrm{~cm}^{-1}$ for the $\mathrm{C}-\mathrm{H}$ bonds of the 
Table 1. The computed geometric parameters of compound $\mathbf{2}$ and comparison with available experimental results for a similar compound, bond lengths in angstrom $(\AA)$ and bond angles in degrees $\left({ }^{\circ}\right)$.

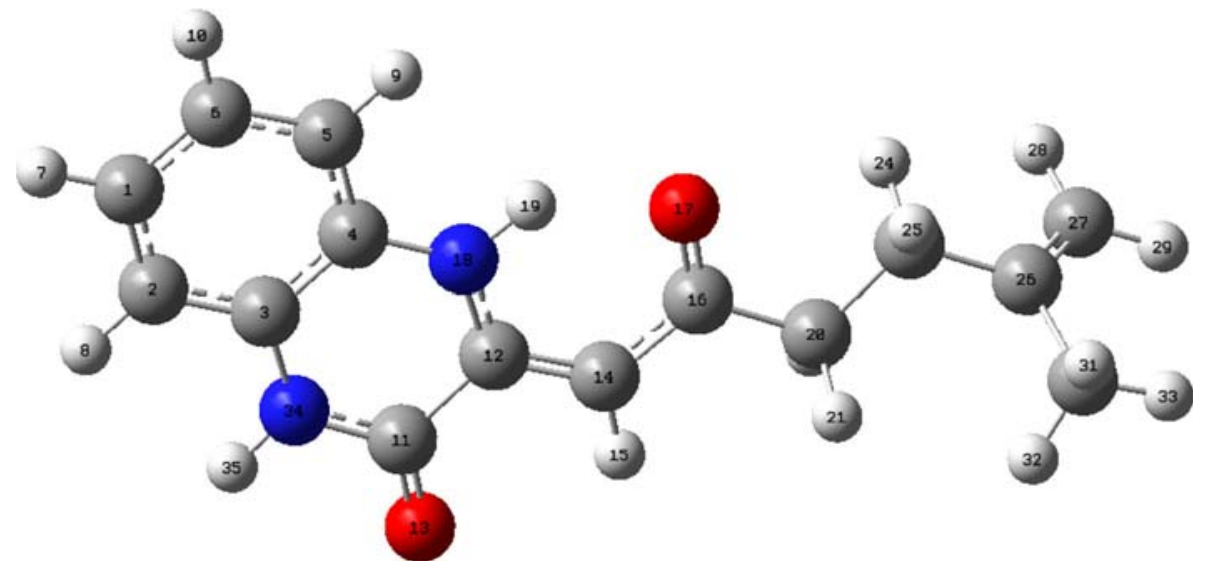

\begin{tabular}{lcccc}
\hline Bond lengths & B3LYP/6-311+G(d,p) & Exper. ${ }^{13}$ & Bond angles & B3LYP/6-311+G(d,p) \\
\hline $\mathrm{C}(1)-\mathrm{C}(2)$ & 1.391 & & $\mathrm{C}(2)-\mathrm{C}(1)-\mathrm{C}(6)$ & 120.1 \\
$\mathrm{C}(1)-\mathrm{C}(6)$ & 1.397 & & $\mathrm{C}(1)-\mathrm{C}(2)-\mathrm{C}(3)$ & 119.9 \\
$\mathrm{C}(2)-\mathrm{C}(3)$ & 1.395 & & $\mathrm{C}(2)-\mathrm{C}(3)-\mathrm{C}(4)$ & 120.1 \\
$\mathrm{C}(3)-\mathrm{C}(4)$ & 1.404 & 1.386 & $\mathrm{C}(2)-\mathrm{C}(3)-\mathrm{N}(34)$ & 122.2 \\
$\mathrm{C}(3)-\mathrm{N}(34)$ & 1.397 & 1.384 & $\mathrm{C}(4)-\mathrm{C}(3)-\mathrm{N}(34)$ & 117.7 \\
$\mathrm{C}(4)-\mathrm{C}(5)$ & & $\mathrm{C}(3)-\mathrm{C}(4)-\mathrm{C}(5)$ & 119.6 \\
$\mathrm{C}(4)-\mathrm{N}(18)$ & 1.398 & 1.382 & $\mathrm{C}(3)-\mathrm{C}(4)-\mathrm{N}(18)$ & 118.5 \\
$\mathrm{C}(5)-\mathrm{C}(6)$ & 1.385 & & $\mathrm{C}(5)-\mathrm{C}(4)-\mathrm{N}(18)$ & 121.9 \\
$\mathrm{C}(11)-\mathrm{C}(12)$ & 1.389 & 1.494 & $\mathrm{C}(4)-\mathrm{C}(5)-\mathrm{C}(6)$ & 120.0 \\
$\mathrm{C}(11)-\mathrm{O}(13)$ & 1.502 & 1.193 & $\mathrm{C}(1)-\mathrm{C}(6)-\mathrm{C}(5)$ & 120.2 \\
$\mathrm{C}(11)-\mathrm{N}(34)$ & 1.217 & & $\mathrm{C}(12)-\mathrm{C}(11)-\mathrm{O}(13)$ & 123.1 \\
$\mathrm{C}(12)-\mathrm{C}(14)$ & 1.376 & $\mathrm{C}(12)-\mathrm{C}(11)-\mathrm{N}(34)$ & 114.9 \\
$\mathrm{C}(12)-\mathrm{N}(18)$ & 1.370 & 1.351 & $\mathrm{O}(13)-\mathrm{C}(11)-\mathrm{N}(34)$ & 122.0 \\
$\mathrm{C}(14)-\mathrm{C}(16)$ & 1.364 & 1.444 & $\mathrm{C}(11)-\mathrm{C}(12)-\mathrm{C}(14)$ & 119.2 \\
$\mathrm{C}(16)-\mathrm{O}(17)$ & 1.447 & $\mathrm{C}(11)-\mathrm{C}(12)-\mathrm{N}(18)$ & 117.7 \\
$\mathrm{C}(16)-\mathrm{C}(20)$ & 1.238 & $\mathrm{C}(14)-\mathrm{C}(12)-\mathrm{N}(18)$ & 123.1 \\
$\mathrm{C}(20)-\mathrm{C}(23)$ & 1.52 & 1.493 & $\mathrm{C}(12)-\mathrm{C}(14)-\mathrm{C}(16)$ & 122.6 \\
$\mathrm{C}(23)-\mathrm{C}(26)$ & 1.534 & 1.526 & $\mathrm{C}(14)-\mathrm{C}(16)-\mathrm{O}(17)$ & 122.5 \\
$\mathrm{C}(26)-\mathrm{C}(27)$ & 1.512 & 1.473 & $\mathrm{C}(14)-\mathrm{C}(16)-\mathrm{C}(20)$ & 116.9 \\
$\mathrm{C}(26)-\mathrm{C}(30)$ & 1.335 & 1.351 & $\mathrm{O}(17)-\mathrm{C}(16)-\mathrm{C}(20)$ & 120.6 \\
& 1.509 & & $\mathrm{C}(4)-\mathrm{N}(18)-\mathrm{C}(12)$ & 125.1 \\
& & & $\mathrm{C}(16)-\mathrm{C}(20)-\mathrm{C}(23)$ & 113.5 \\
& & & $\mathrm{C}(20)-\mathrm{C}(23)-\mathrm{C}(26)$ & 113.1 \\
& & $\mathrm{C}(23)-\mathrm{C}(26)-\mathrm{C}(26)-\mathrm{C}(30)$ & 121.6 \\
& & $\mathrm{C}(27)-\mathrm{C}(26)-\mathrm{C}(30)$ & 116.5 \\
& & & $\mathrm{C}(3)-\mathrm{N}(34)-\mathrm{C}(11)$ & 121.9 \\
& & & & 126.1 \\
\hline
\end{tabular}

phenyl ring that is part of benzoyl fragment (for compounds 1, 3 and 4). Experimental values for aromatic $\mathrm{C}-\mathrm{H}$ stretching were found to be at 3143 , 3037 and $2963 \mathrm{~cm}^{-1}$ for the $\mathrm{C}-\mathrm{H}$ bonds of the aromatic ring bearing quinoxalinone scaffold in all cases, and at 3143,3043 and $3002 \mathrm{~cm}^{-1}$ for the $\mathrm{C}-\mathrm{H}$ bonds of the phenyl ring that is part of benzoyl fragment.

The aliphatic $\mathrm{C}-\mathrm{H}$ stretching vibrations of the methoxy group were calculated at 3046, 2989 and
$2926 \mathrm{~cm}^{-1}$ for compound 1, vibrations of the methyl group for compound $\mathbf{2}$ were calculated at 3033, 3010 and $2900 \mathrm{~cm}^{-1}$ and the $\mathrm{C}-\mathrm{H}$ stretching vibrations of methyl group for compound $\mathbf{4}$ were calculated at 3055, 2995 and $2937 \mathrm{~cm}^{-1}$. Experimental values for aliphatic C-H stretching were found to be 2965, 2854 and $2811 \mathrm{~cm}^{-1}$ for compounds $\mathbf{1}, 2$ and 4.

3.2b $C-C$ vibrations: For heteronuclear aromatic compounds, the stretching vibrations of the $\mathrm{C}-\mathrm{C}$ bonds 
Table 2. Comparison of the selected calculated and experimental vibrational modes and proposal assignments of compound $\mathbf{1}$.

\begin{tabular}{|c|c|c|c|c|}
\hline \multirow[b]{2}{*}{ Unscaled $\left(\mathrm{cm}^{-1}\right)$} & \multirow[b]{2}{*}{ Scaled $\left(\mathrm{cm}^{-1}\right)$} & \multicolumn{2}{|c|}{ Observed frequencies } & \multirow[b]{2}{*}{ Vibrational assignments (TED\%) } \\
\hline & & FT-IR & FT-Raman & \\
\hline 3572 & 3457 & 3437 & & $v \mathrm{~N}_{11} \mathrm{H}_{13}(79)$ \\
\hline 3327 & 3220 & & & $v \mathrm{~N}_{12} \mathrm{H}_{14}(70)$ \\
\hline 3252 & 3147 & & & $v \mathrm{C}_{18} \mathrm{H}_{19}(64)$ \\
\hline 3210 & 3107 & & & $v \mathrm{C}_{24} \mathrm{H}_{28}(30)+v \mathrm{C}_{27} \mathrm{H}_{31}(45)$ \\
\hline 3200 & 3097 & & & $v \mathrm{C}_{1} \mathrm{H}_{7}(28)+v_{6} \mathrm{H}_{10}(28)+v \mathrm{C}_{5} \mathrm{H}_{9}(13)+v \mathrm{C}_{2} \mathrm{H}_{8}(10)$ \\
\hline 3199 & 3096 & & 3079 & $v \mathrm{C}_{23} \mathrm{H}_{26}(38)$ \\
\hline 3195 & 3092 & & & $v \mathrm{C}_{24} \mathrm{H}_{28}(43)+v \mathrm{C}_{27} \mathrm{H}_{31}(28)$ \\
\hline 3189 & 3086 & & & $v \mathrm{C}_{1} \mathrm{H}_{7}(25)+v_{6} \mathrm{H}_{10}(19)+v \mathrm{C}_{5} \mathrm{H}_{9}(25)+v \mathrm{C}_{2} \mathrm{H}_{8}(15)$ \\
\hline 3184 & 3081 & & & $v \mathrm{C}_{23} \mathrm{H}_{26}(28)+v \mathrm{C}_{25} \mathrm{H}_{30}(42)$ \\
\hline 3178 & 3076 & & & $v \mathrm{C}_{5} \mathrm{H}_{9}(33)+v_{6} \mathrm{H}_{10}(24)+v_{2} \mathrm{H}_{8}(21)$ \\
\hline 3172 & 3070 & 3037 & & $v \mathrm{C}_{1} \mathrm{H}_{7}(21)+v \mathrm{C}_{6} \mathrm{H}_{10}(14)+v \mathrm{C}_{5} \mathrm{H}_{9}(11)+v \mathrm{C}_{2} \mathrm{H}_{8}(34)$ \\
\hline 3147 & 3046 & 3002 & & $v \mathrm{C}_{33} \mathrm{H}_{35}(53)+\gamma \mathrm{C}_{33} \mathrm{H}_{36}(13)+\gamma \mathrm{C}_{33} \mathrm{H}_{34}(13)$ \\
\hline 3089 & 2989 & 2965 & & $v_{\text {asym }} \mathrm{C}_{33} \mathrm{H}_{34} \mathrm{H}_{36}(40)$ \\
\hline 3023 & 2926 & & & $v_{\text {sym }} \mathrm{C}_{33} \mathrm{H}_{34} \mathrm{H}_{36}(36)$ \\
\hline 1720 & 1664 & 1681 & 1628 & $v \mathrm{C}_{15} \mathrm{O}_{17}(15)$ \\
\hline 1610 & 1558 & 1597 & 1580 & $v(\mathrm{C}-\mathrm{C})_{\text {aromatic }}$ \\
\hline 1529 & 1479 & 1518 & 1553 & $\beta \mathrm{C}_{4} \mathrm{~N}_{12} \mathrm{C}_{16}(6)+\beta \mathrm{C}_{3} \mathrm{~N}_{11} \mathrm{C}_{15}(6)$ \\
\hline 1500 & 1451 & 1510 & & $\beta \mathrm{C}_{33} \mathrm{H}_{34} \mathrm{H}_{36}(23)+\beta \mathrm{C}_{33} \mathrm{H}_{35} \mathrm{H}_{36}(12)$ \\
\hline 1498 & 1449 & 1500 & & $v C_{1} C_{2}+v C_{1} C_{6}+v C_{5} C_{6}+v C_{5} C_{4}(6)+\beta C_{29} O_{32} C_{33}(10)$ \\
\hline 1493 & 1445 & 1445 & 1445 & $v \mathrm{C}_{33} \mathrm{H}_{35}(24)+\gamma \mathrm{C}_{33} \mathrm{H}_{36}(21)$ \\
\hline 1488 & 1440 & 1436 & 1424 & $\beta \mathrm{C}_{16} \mathrm{C}_{18} \mathrm{H}_{19}(6)+\beta \mathrm{C}_{16} \mathrm{C}_{18} \mathrm{C}_{20}(6)$ \\
\hline 1468 & 1420 & 1416 & 1410 & $\mathrm{\beta C}_{33} \mathrm{H}_{34} \mathrm{H}_{36}(9)$ \\
\hline 1442 & 1395 & & 1392 & $\beta \mathrm{H}_{13} \mathrm{~N}_{11} \mathrm{C}_{15}$ \\
\hline 1385 & 1340 & 1373 & 1320 & $\beta \mathrm{C}_{15} \mathrm{C}_{16} \mathrm{~N}_{12}(6)+\beta \mathrm{C}_{18} \mathrm{C}_{16} \mathrm{~N}_{12}(6)$ \\
\hline 1181 & 1143 & & & $\begin{array}{l}\beta \mathrm{C}_{1} \mathrm{C}_{6} \mathrm{H}_{10}(11)+\beta \mathrm{C}_{6} \mathrm{C}_{1} \mathrm{H}_{7}(11)+\beta \mathrm{C}_{5} \mathrm{C}_{6} \mathrm{H}_{10}(11) \\
+\beta \mathrm{C}_{2} \mathrm{C}_{1} \mathrm{H}_{7}(11)\end{array}$ \\
\hline 1161 & 1123 & 1155 & & $\gamma \mathrm{C}_{33} \mathrm{H}_{34}(20)+\gamma \mathrm{C}_{33} \mathrm{H}_{36}(21)$ \\
\hline 1052 & 1018 & & & $v C_{1} C_{6}(11)$ \\
\hline 1034 & 1000 & & & $\mathrm{vC}_{32} \mathrm{C}_{33}(21)$ \\
\hline
\end{tabular}

were found to be in the narrow ranges of 1600-1585 and $1500-1400 \mathrm{~cm}^{-1} \cdot{ }^{24}$ Vibrations of aromatic C-C bond that are calculated have values around 1558 and $1340 \mathrm{~cm}^{-1}$. Experimental vibrations are 1553 and $1351 \mathrm{~cm}^{-1}$. As can be seen, matching between experimental and calculated values are excellent. The stretching vibrations of aliphatic $\mathrm{C}-\mathrm{C}$ bonds for compound 2 were calculated at $1412 \mathrm{~cm}^{-1}$ and it was assigned to the band at $1380 \mathrm{~cm}^{-1}$ in the experimental FT-IR spectrum.

3.2c $\mathrm{N}-\mathrm{H}$ vibrations: For $\mathrm{N}-\mathrm{H}$ stretching vibration is found to be in the region of $3300-3500 \mathrm{~cm}^{-1} \cdot{ }^{25} \mathrm{~N}-$ $\mathrm{H}$ stretching vibrations for compound $\mathbf{1}$ were calculated at 3457 and $3220 \mathrm{~cm}^{-1}$, for compound $\mathbf{2}$ at 3472 and $3070 \mathrm{~cm}^{-1}$, for compound 3 at 3460 and $3191 \mathrm{~cm}^{-1}$ and for compound 4 at 3480 and $3455 \mathrm{~cm}^{-1}$. These values have a good match with experimental values that are 3473 (1), 3412 (2), 3438 and $3411(\mathbf{3})$ and $3484 \mathrm{~cm}^{-1}$ (4). Also, in experimental spectra there are no two values for $\mathrm{N}-\mathrm{H}$ stretching (except for compound 3) but only one broad band.

3.2d $C=O$ vibrations: Carbonyl $(\mathrm{C}=\mathrm{O})$ group stretching vibration is expected to appear in the region of $1680-1715 \mathrm{~cm}^{-1} .{ }^{26}$ For quinoxalinones (1, 2, 3) amide carbonyl group stretching vibration appear around $1700 \mathrm{~cm}^{-1}$ as a strong band in experimental spectra. The calculated value for this stretching vibration is around $1690 \mathrm{~cm}^{-1}$. For oxazinone (4) ester carbonyl group stretching vibration appear at $1754 \mathrm{~cm}^{-1}$ in experimental spectrum. The value of $v_{\mathrm{C}=\mathrm{O}}$ band is calculated at $1756 \mathrm{~cm}^{-1}$. Experimental values for carbonyl group stretching vibration from benzoyl fragment for all tested compounds are in range of $1605-1650 \mathrm{~cm}^{-1}$. 

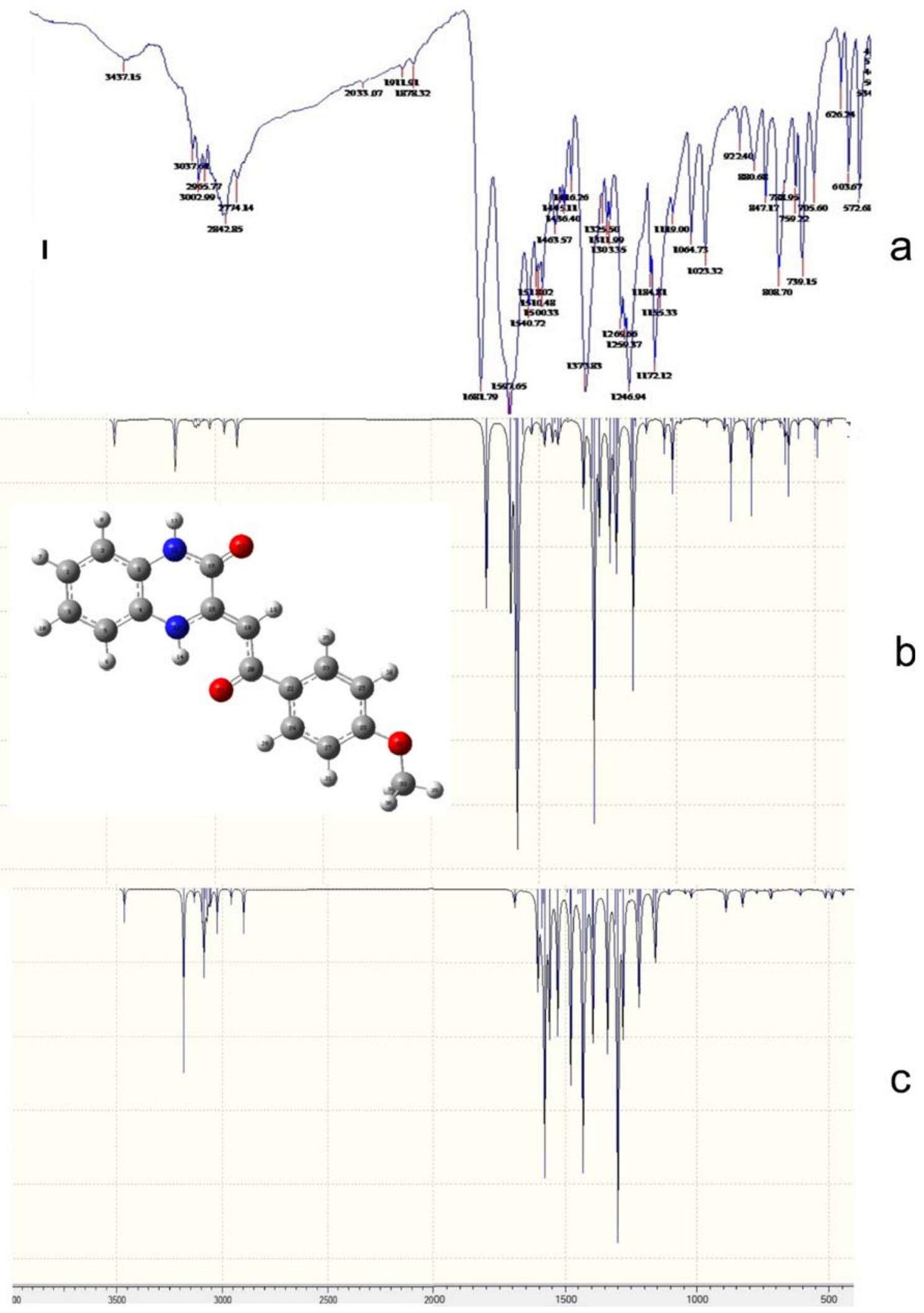

Figure 2. Experimental (a), calculated IR (b) and calculated Raman (c) for compound 1 (picture I) and compound 2 (picture II). 


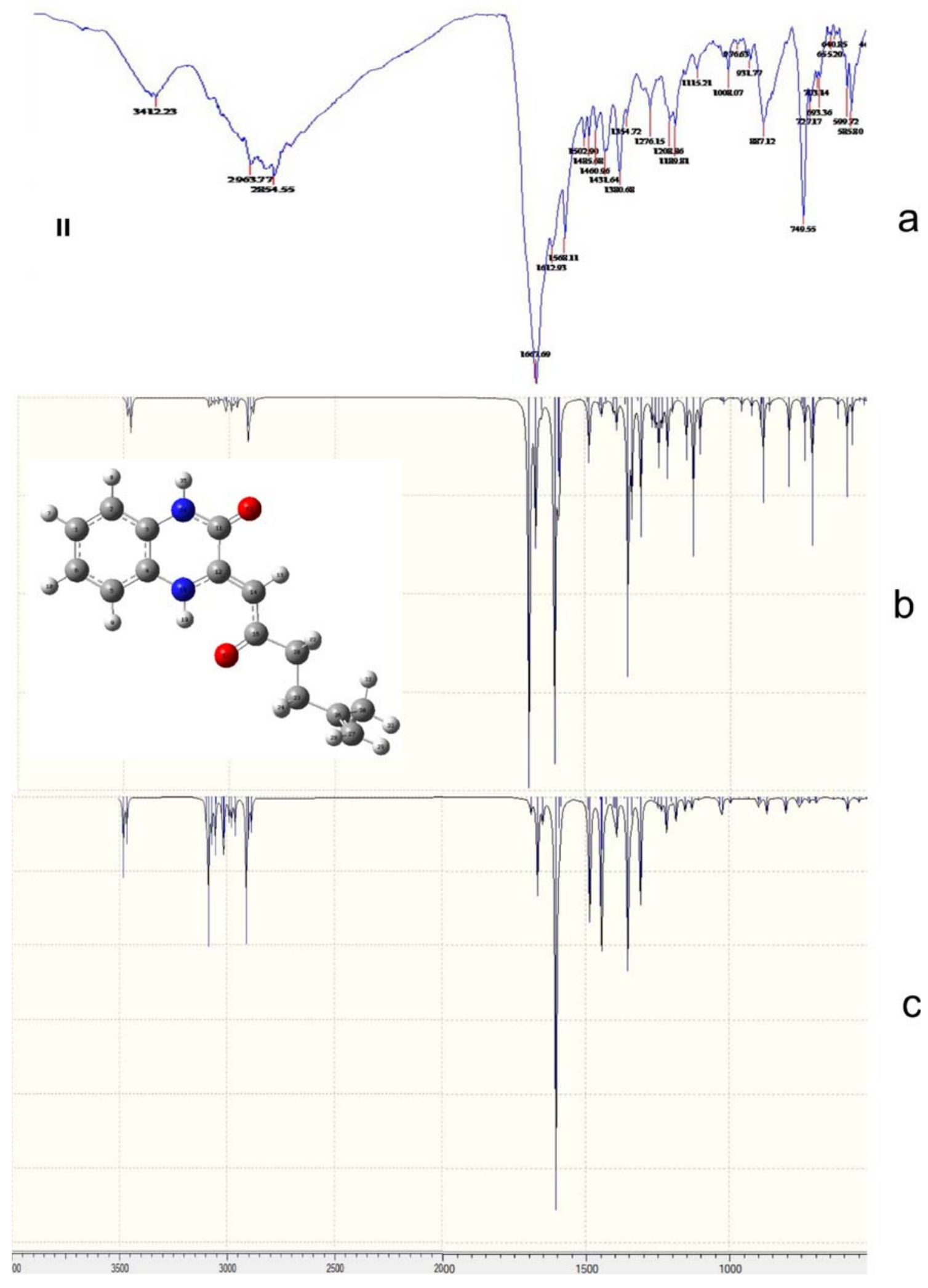

Figure 2. continued

Calculated values are in the range of experimental value $1599 \mathrm{~cm}^{-1}$ and calculated value $1600-1680 \mathrm{~cm}^{-1}$. The value of $v_{\mathrm{C}=\mathrm{O}}$ band from is $1645 \mathrm{~cm}^{-1}$. Experimental and calculated values of $\mathrm{NHCOCH}_{3}$ fragment (compound 4) has an $\mathrm{C}=\mathrm{O}$ stretching vibration are perfectly match. 


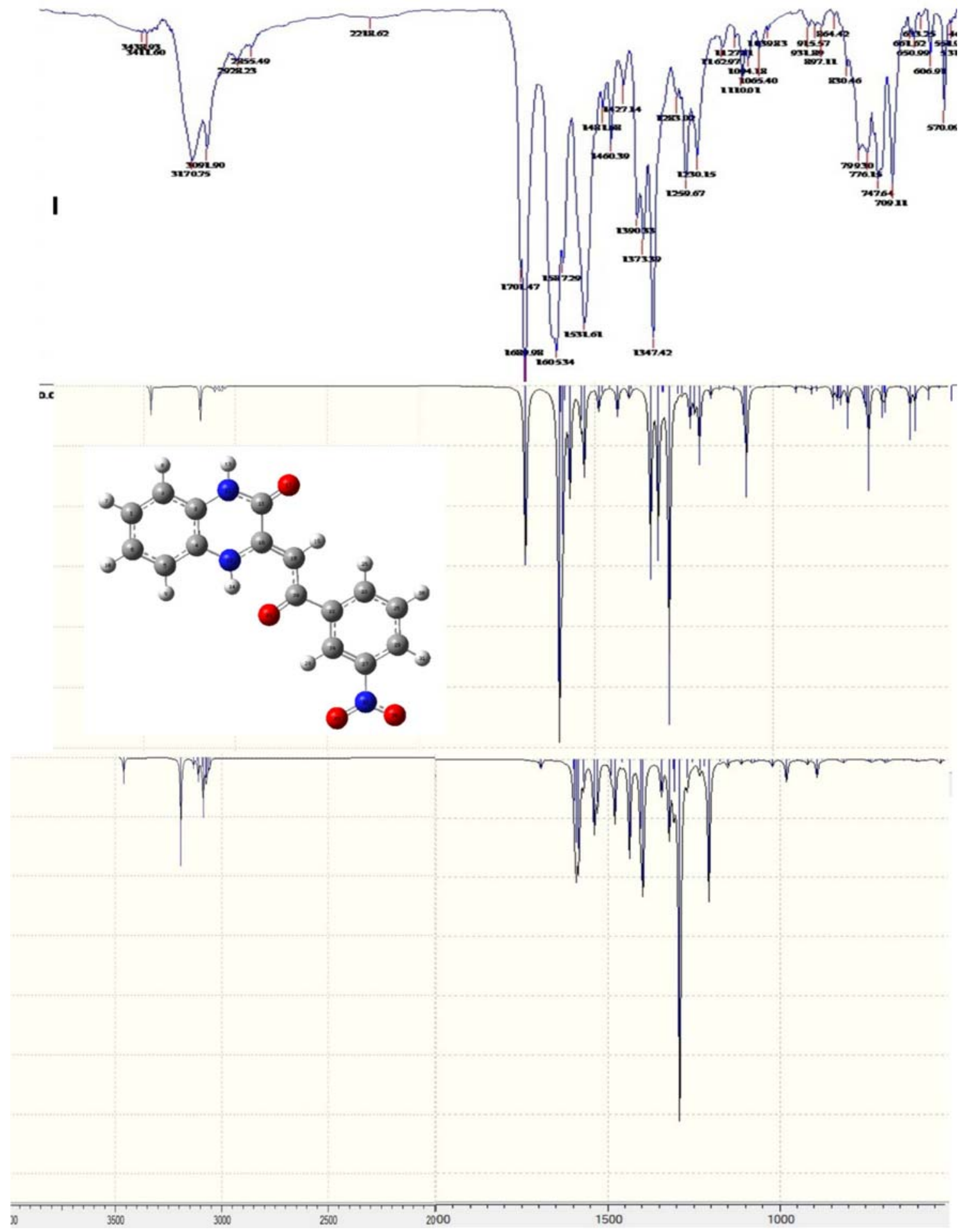

Figure 3. Experimental (a), calculated IR (b) and calculated Raman (c) for compound $\mathbf{3}$ (picture I) and compound 4 (picture II).

\subsection{Raman activities}

The results presented here are obtained using the laser with $\lambda=780 \mathrm{~nm}$ and the laser power level set to $10 \mathrm{~mW}$. The experimental results were compared with theoretically predicted and simulated vibrations. $\mathrm{C}-\mathrm{H}$ stretch vibration around $3000 \mathrm{~cm}^{-1}$ is missing only from spectra of compound 2 due to high noise in that range. ${ }^{27}$ The bands around $1540 \mathrm{~cm}^{-1}$ and $1560 \mathrm{~cm}^{-1}$ in compounds $\mathbf{1 - 2}$ and 


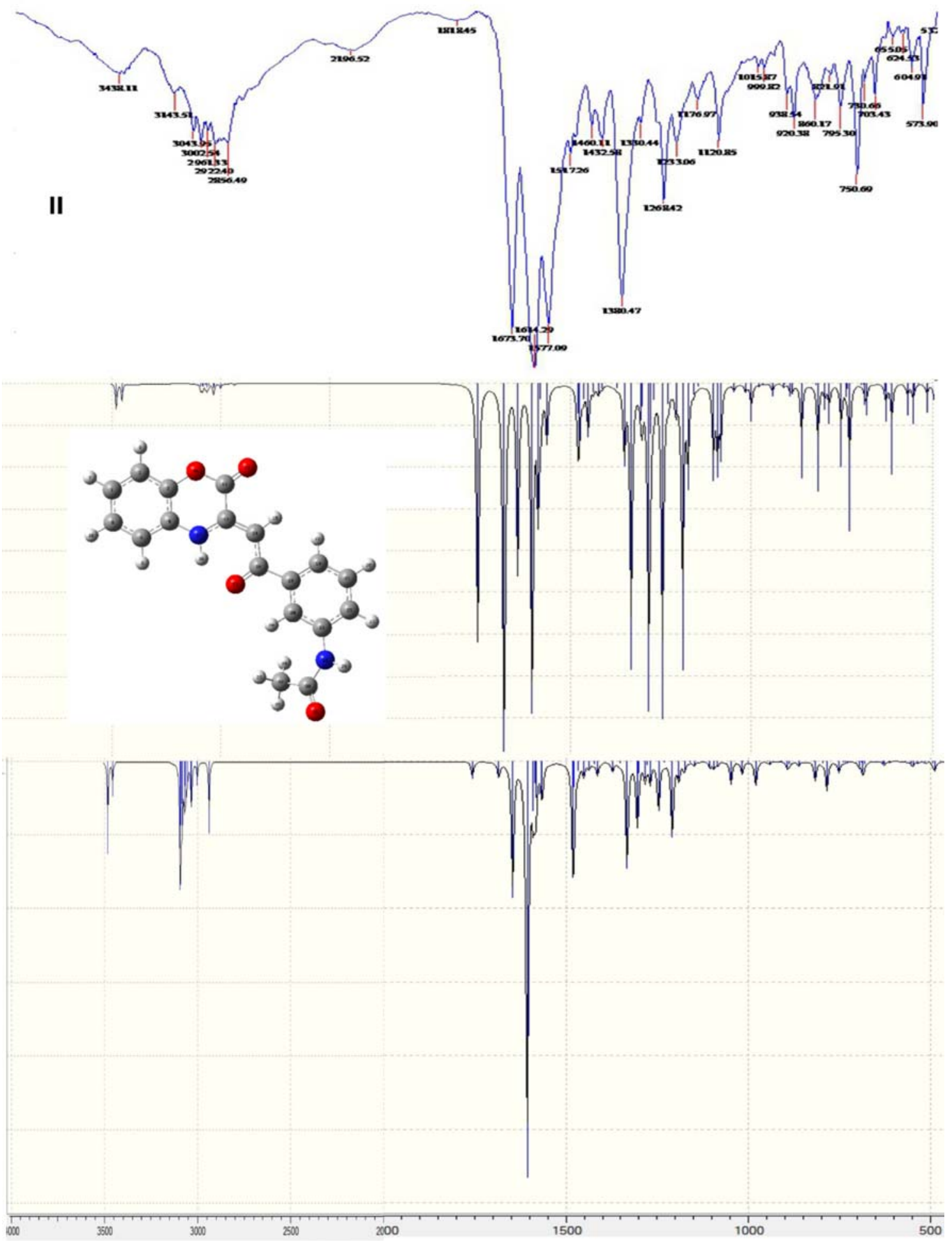

Figure 3. continued

compounds 3-4, respectively, have been attributed to $\mathrm{C}-\mathrm{N}-\mathrm{H}$ vibrations. One of the peaks with the highest intensities in spectra of compounds $\mathbf{1 - 3}$ in the near $1330-1380 \mathrm{~cm}^{-1}$ arises from $\mathrm{C}-\mathrm{O}$ stretching. ${ }^{28}$ The strongest peak in spectra of compound $\mathbf{4}$ arises from the benzene ring oscillations, as theory predicts around $1500 \mathrm{~cm}^{-1}$ (in collected spectra $1498 \mathrm{~cm}^{-1}$ ). Peaks in the region of $1235-1275 \mathrm{~cm}^{-1}$ correspond to the asymmetric bending of $\mathrm{N}-\mathrm{O}$ bonds in the compounds. $\mathrm{C}-\mathrm{O}-\mathrm{C}$ symmetric stretch vibration modes ${ }^{29}$ can be found at $1000-1050 \mathrm{~cm}^{-1}$ (Figures 4 and 5). 
Collected Raman spectra for compound $\mathbf{3}$ have shown very low peak intensity and a lot of noise in the spectra. This may be explained with the morphology of the sample and the ratio of the crystallinity and the amorphous phase in the sample. Samples with higher crystallinity had higher peak intensities. Confirmation for this comes from the microscopy images taken during Raman spectroscopy analysis with Olympus light microscope coupled with 10 magnification objective (Figure 6).

The vibrations of the analyzed samples are well identified in the collected spectra within their characteristic regions and their calculated peak values coincide very well with the experimental values. Some differences between collected and calculated spectra can be observed. This is partly due to the approximate nature of the quantum mechanical models of vibration calculations. Also, some deviations of calculated wavenumbers compared to the experimental results can be attributed to the underestimation of the large degree of $\pi$-electron delocalization due to conjugation of the molecule.

\subsection{Electronic absorption analysis}

The absorption wavelengths correspond to the electronic transition from the ground to the first excited state. Electron absorption is described by one electron excitation from the highest occupied molecular orbital (HOMO) to the lowest unoccupied molecular orbital (LUMO). The frontier molecular orbitals and energy difference between HOMO and LUMO play an important role in the electric and optical properties. Common types of electronic transitions in organic molecules are $\pi-\pi^{*}, \mathrm{n}-\pi^{*}$ and $\pi^{*}$ (acceptor) $-\pi$ (donor). The experimental UV spectrum of compound $\mathbf{1}$ is shown in Figure 7. The experimental absorption wavelengths (energies) and computed electronic values, such as absorption wavelengths $(\lambda)$, excitation energies (E), oscillator strengths (f) and orbital description are tabulated in Table 3. HOMO and LUMO orbitals are of crucial importance in chemical reactions. The HOMO energy corresponds to the ability of electron giving while LUMO energy corresponds to the ability of electron-accepting. Difference between HOMO and LUMO energy (gap energy) characterizes the molecular chemical stability. The TD-DFT calculations were carried out using B3LYP/ $6-311+\mathrm{G}(\mathrm{d}, \mathrm{p})$ level of theory and solvation model $\mathrm{CPCM}^{30}$ (ethanol solution). The results obtained here give insight into electron transitions from the ground state to excited state at the molecular orbital level.

For compound $\mathbf{1}$ the absorption of UV radiation with a wavelength of $412 \mathrm{~nm}$ with an oscillator strength $f=0.95$ induces the intramolecular electronic
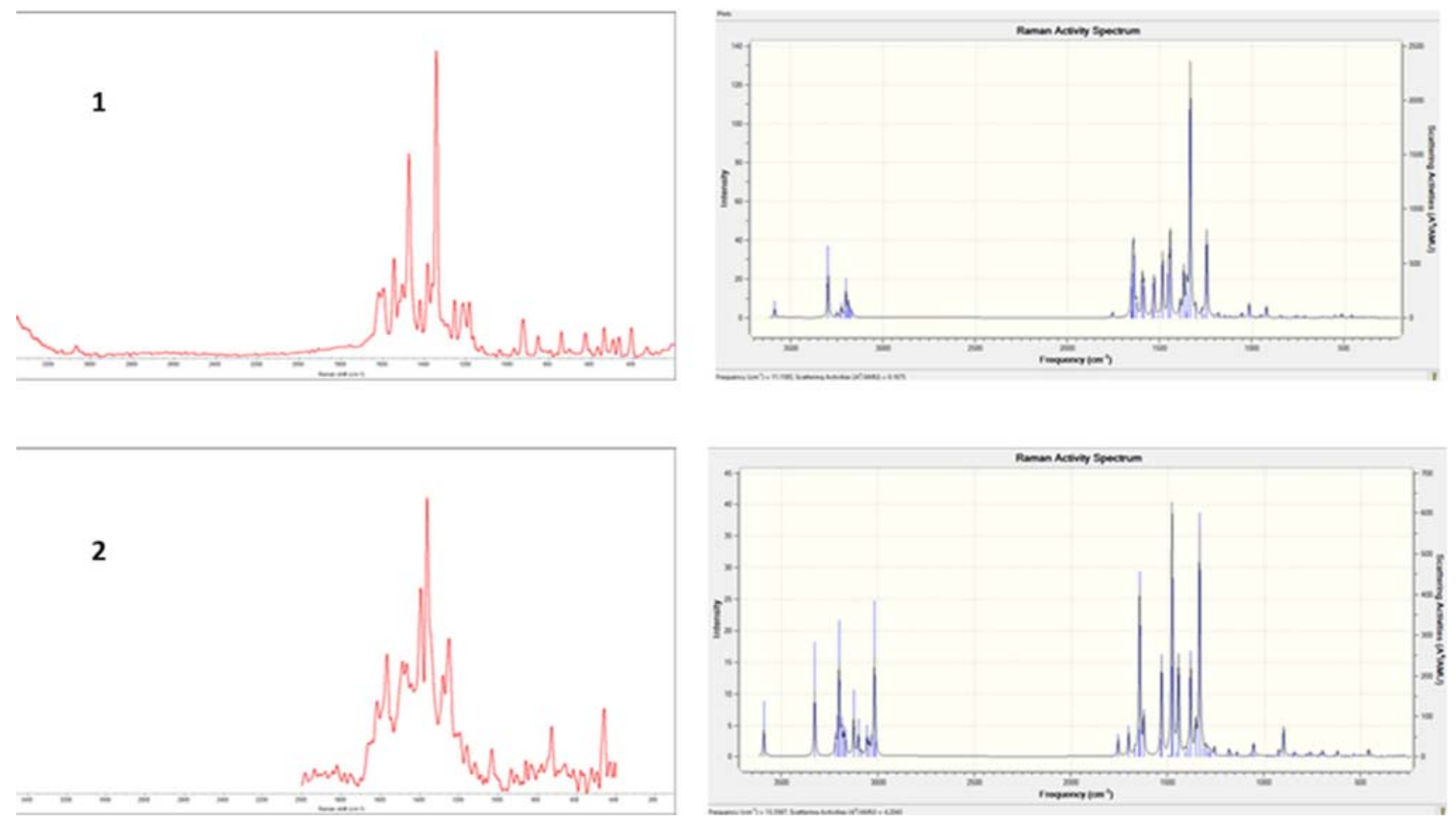

Figure 4. Experimental results of Raman spectroscopy of the compounds $\mathbf{1}$ and 2. 

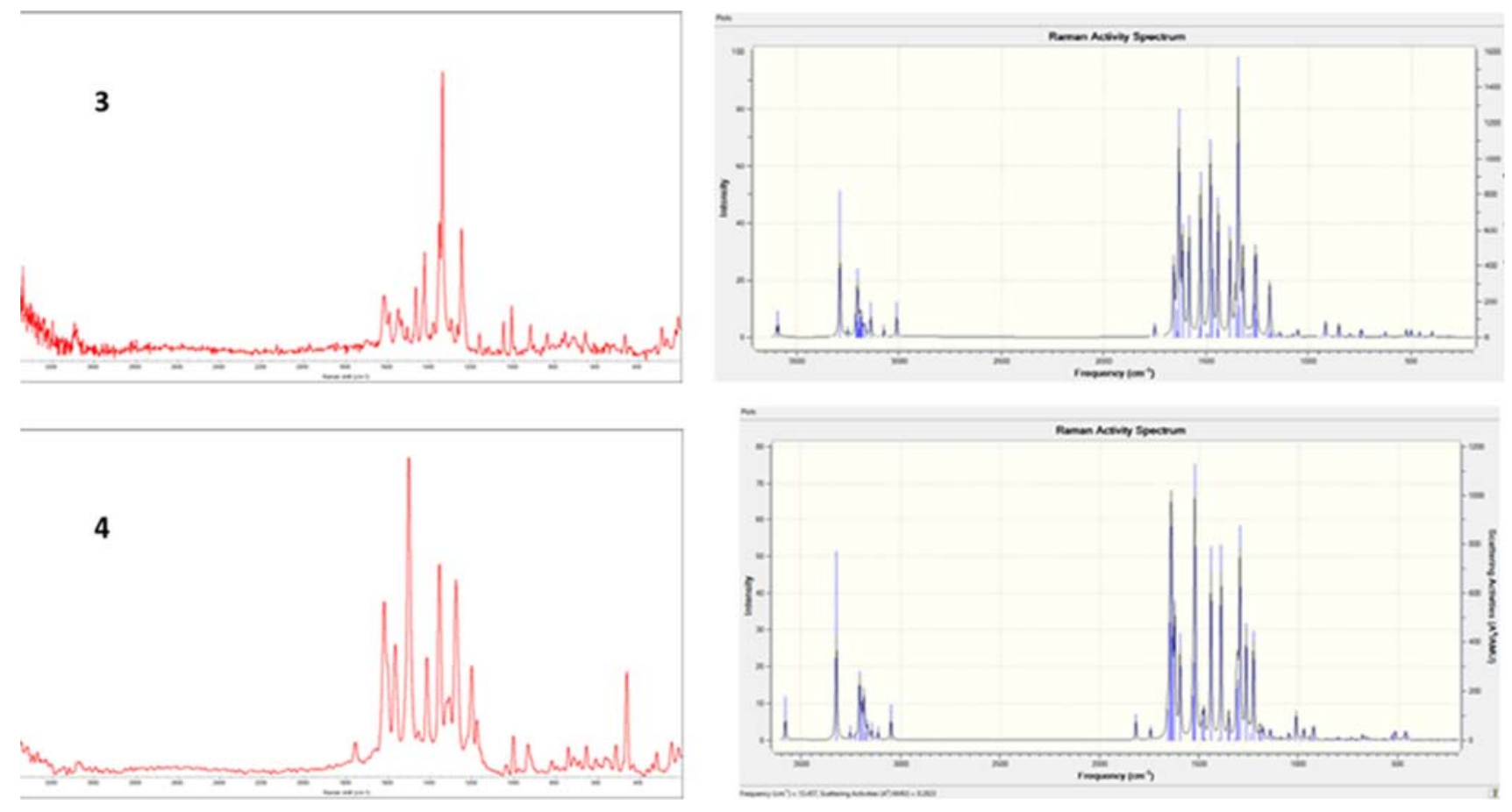

Figure 5. Experimental results of Raman spectroscopy of compounds 3 and $\mathbf{4}$.

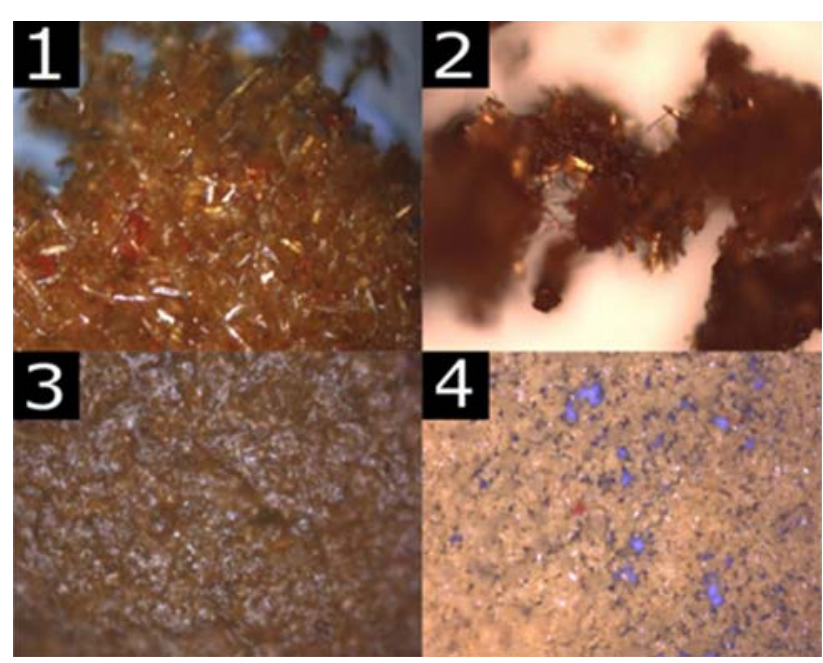

Figure 6. Microscopy images taken during Raman spectroscopy analysis.

transition $n \rightarrow \pi^{*}$. The other absorption band calculated at $228 \mathrm{~nm}$ with an oscillator strength $\mathrm{f}=0.33$ induces the intramolecular transition with $\mathrm{n} \rightarrow \pi^{*}$ and $\pi \rightarrow \pi^{*}$ character. In consideration of calculated absorption spectra, the maximum absorption wavelength corresponds to the electronic transition from the HOMO to LUMO with $70 \%$ and from the HOMO to LUMO+1 also with $70 \%$ contribution. The frontier molecular orbitals (FMOs) for compound $\mathbf{1}$ are presented in Figure 8. For compounds $\mathbf{2}, \mathbf{3}$ and $\mathbf{4}$ simulated UV-Vis spectra and HOMO-LUMO orbitals see
Supplementary Information. The simulated FMOs from Figure 8 indicates the presence of intramolecular charge transfer within the whole molecule. Similar charge transfer regarding the LUMO orbitals is obtained for compounds $\mathbf{3}$ and $\mathbf{4}$, while in the case of compound $\mathbf{2}$ electron transfer is located on quinoxaline scaffold as a consequence of the absence of benzoyl fragment. Electron charge transfer concerning the HOMO orbitals for compounds $\mathbf{2} \mathbf{- 4}$ is distributed only through heterocyclic rings (Figures S4-S6, Supplementary Information).

In previously published papers it can be found that many of the organic compounds used as corrosion inhibitors are heterocyclic compounds that contain polar functional groups such as $-\mathrm{OH},-\mathrm{OCH}_{3},-\mathrm{Cl}$, $-\mathrm{NO}_{2},-\mathrm{CN},-\mathrm{C}=\mathrm{N}-,-\mathrm{CH}_{3},-\mathrm{NH}_{2}$, etc., or unsaturated (double and triple) bonds that can serve as adsorption centers due to the presence of $\pi$-electrons or nonbonding pair. ${ }^{31-33}$ In most cases, the presence of electron-donating groups such as $-\mathrm{OH},-\mathrm{NH}_{2},-\mathrm{CH}_{3}$, $-\mathrm{OCH}_{3}$ etc., increases the inhibition performance because that group increases the electron density at the inhibitor's adsorption center and thus increase interactions between the inhibitor and the metallic surface. On the other hand, the presence of electron-withdrawing groups such as $-\mathrm{NO}_{2},-\mathrm{CN}, \mathrm{COOH}$, $-\mathrm{COOC}_{2} \mathrm{H}_{5}$ decreases the inhibition efficiency of organic molecules because that group decreases the 


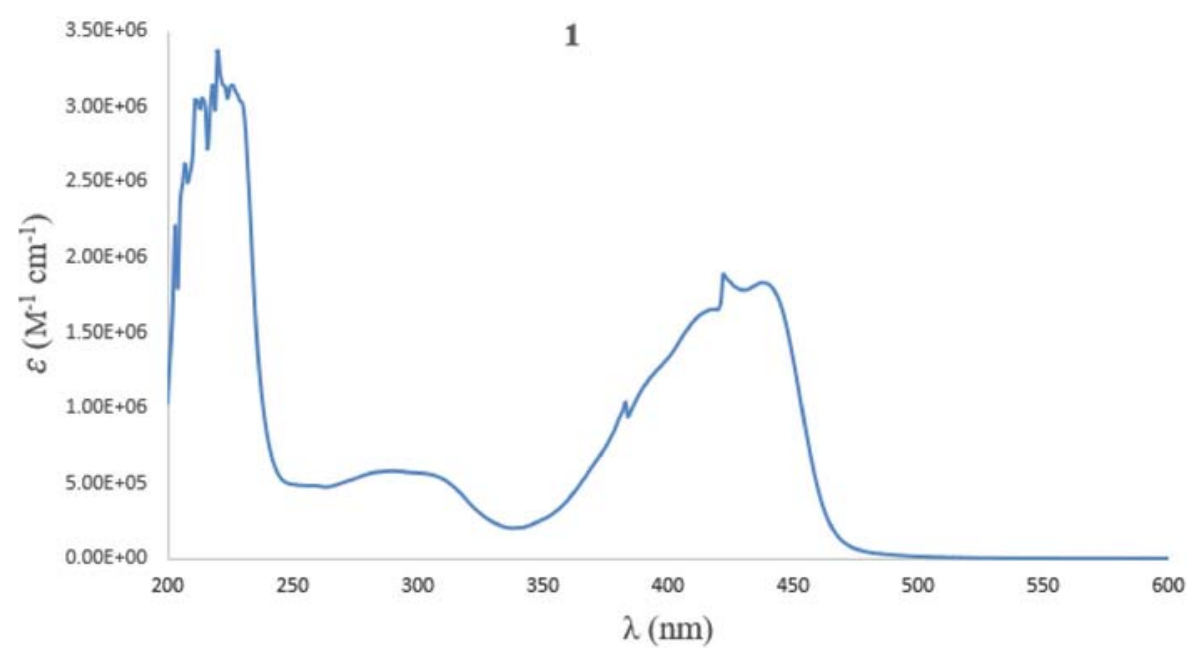

Figure 7. Experimental UV-Vis spectrum of compound $\mathbf{1}$.

Table 3. Experimental and theoretical electronic absorption spectra of selected compounds $(\mathbf{1}, 2,3$ and 4) (absorption wavelength $\lambda(\mathrm{nm})$, excitation energies $\mathrm{E}(\mathrm{eV})$ and oscillator strengths (f)) using TD-DFT/B3LYP/6-311+G(d,p) method in ethanol as solvent.

\begin{tabular}{ccccccl}
\hline & \multirow{2}{*}{$\begin{array}{c}\text { Experimental } \\
\lambda(\mathrm{nm})\end{array}$} & \multicolumn{5}{c}{ TD-DFT (B3LYP/6-311+G(d,p)) } \\
\cline { 3 - 7 } Compounds $(\mathrm{eV})$ & $\lambda(\mathrm{nm})$ & $\mathrm{E}(\mathrm{eV})$ & $\mathrm{f}$ & Orbital description \\
\hline \multirow{2}{*}{1} & 422 & 2.93 & 412 & 3.00 & 0.95 & $\mathrm{H} \rightarrow \mathrm{L}(70 \%)$ \\
& 270 & 4.37 & 228 & 5.43 & 0.33 & $\mathrm{H}-2 \rightarrow \mathrm{L}+1(61 \%)$ \\
2 & 400 & 3.09 & 377 & 3.28 & 0.59 & $\mathrm{H} \rightarrow \mathrm{L}(70 \%)$ \\
& 275 & 4.49 & 219 & 5.66 & 0.14 & $\mathrm{H}-2 \rightarrow \mathrm{L}+2(58 \%)$ \\
3 & 425 & 2.87 & 417 & 2.97 & 0.78 & $\mathrm{H} \rightarrow \mathrm{L}+1(70 \%)$ \\
& 260 & 4.74 & 270 & 4.58 & 0.06 & $\mathrm{H}-4 \rightarrow \mathrm{L}+1(60 \%)$ \\
& 420 & 2.93 & 421 & 2.94 & 0.73 & $\mathrm{H} \rightarrow \mathrm{L}(70 \%)$ \\
& 255 & 4.81 & 228 & 5.42 & 0.11 & $\mathrm{H}-2 \rightarrow \mathrm{L}+1(64 \%)$ \\
& & & & & &
\end{tabular}

electron density at the adsorption center of the inhibitor leading to a decrease of the adsorption tendency on metallic surface. ${ }^{34-36}$ With that purpose, we investigated the electronic parameters of selected compounds such as HOMO ( $\left.\mathrm{E}_{\mathrm{HOMO}}\right)$ and LUMO $\left(\mathrm{E}_{\mathrm{LUMO}}\right)$ energies, energy gap $(\Delta \mathrm{E})$, electronegativity $(\chi)$, dipole moment $(\mu)$, electron affinity $(\mathrm{A})$, ionization potential $(\mathrm{I})$, hardness $(\eta)$, softness $(\sigma)$, electron charge transfer $(\Delta \mathrm{N})$. Using the equations below ${ }^{37}$, all these global molecular reactivity descriptors are estimated from the optimized structures (Table 4).

$$
\begin{aligned}
& \Delta E_{\text {gар }}=E_{\text {LUMO }}-E_{\text {НОМO }} \\
& I=-E_{\text {HОМO }} \\
& A=-E_{\text {LUMO }} \\
& \chi=\frac{I+A}{2}
\end{aligned}
$$

$$
\begin{aligned}
& \eta=\frac{I-A}{2} \\
& \sigma=\frac{1}{\eta} \\
& \Delta N=\frac{\chi(F e)-\chi(i n h)}{2(\eta(F e)+\eta(i n h))}
\end{aligned}
$$

The values of $\chi(\mathrm{Fe})$ and $\eta(\mathrm{Fe})$ are taken as $7 \mathrm{eV} / \mathrm{mol}$ and $0 \mathrm{eV} / \mathrm{mol}$ respectively. The calculations for compounds 1, 2, 3 and $\mathbf{4}$ show that compound $\mathbf{1}$ has the highest HOMO energy $(-5.900 \mathrm{eV})$ and compound 4 the lowest LUMO energy at $(-2.928 \mathrm{eV})$ compared to the calculated parameters for compounds $2(-5.961$ and -2.332) and $\mathbf{3}(-6.096$ and $-0.657 \mathrm{eV})$. These results indicate that compound 1 has higher inhibitory efficiency because it has been shown that higher the value of HOMO energy, the lesser is the value of the ionization potential, and the easier it is for the electrons to be donated. ${ }^{38}$ The 


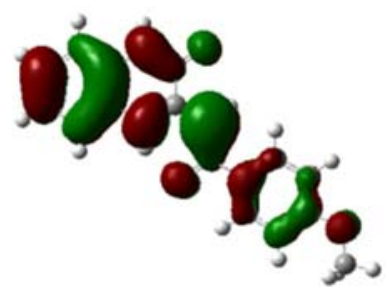

HOMO

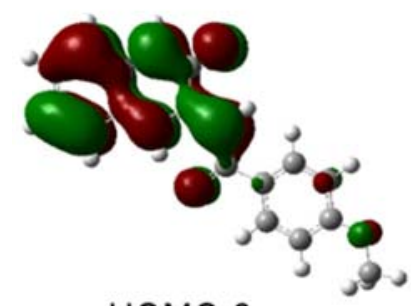

HOMO-2

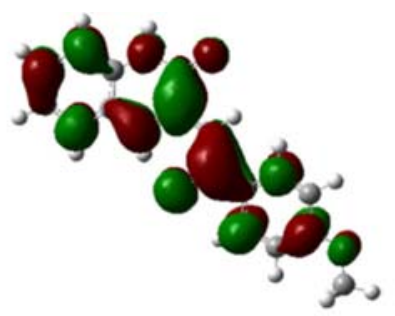

LUMO

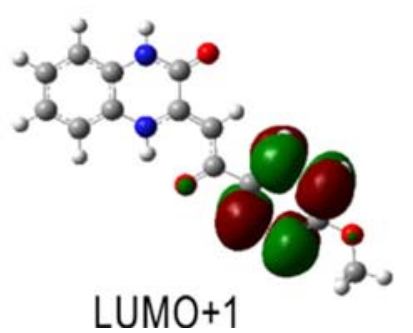

Figure 8. The frontier molecular orbitals for compound 1.

reactivity tendency of the organic molecule towards the metal surface and electrical transport properties are determined by energy gap $(\Delta \mathrm{E})$. Low value of the energy gap will provide good inhibition efficiencies because the energy that is required to remove an electron from the last occupied orbital will be low. Also, the lower value of $\Delta \mathrm{E}_{\text {gap }}$ means the higher stability for the formed complex on the metallic surface. The values of $\Delta \mathrm{E}_{\text {gap }}$ for compounds $\mathbf{1}, \mathbf{2}, \mathbf{3}$ and $\mathbf{4}$ are $3.386,3.629,5.439$ and $3.309 \mathrm{eV}$, respectively. Inhibitor $\mathbf{4}$ has lower energy gap than 1, 2 and $\mathbf{3}$ and this means that the molecule could have better inhibition performance. The bandgap energy value of compound 3 was calculated as $5.439 \mathrm{eV}$, which confirms that the molecule has most stable structure compared to $\mathbf{1}, \mathbf{2}$ and 4 and the $\Delta \mathrm{E}_{\text {gap }}$ is comparable with the value of $\Delta \mathrm{E}_{\text {gap }}$ some bioactive molecules. ${ }^{39}$ The lower value of electron affinity $(0.657 \mathrm{eV}$ for compound 3$)$ shows that the mentioned molecule readily accepts electrons to form bonds; that means the higher molecular reactivity with nucleophiles.

Softness $(\sigma)$ and absolute hardness $(\eta)$ are important properties that are related to molecular stability and reactivity. In accordance with this, inhibition efficiency increases with increasing softness and decreases on increasing the hardness of the molecules. ${ }^{40}$ In comparison with compounds $\mathbf{1}$ $\left(\eta=1.693 \mathrm{eV}, \sigma=0.591 \mathrm{eV}^{-1}\right), \quad 2 \quad(\eta=1.814 \mathrm{eV}$, $\left.\sigma=0.551 \mathrm{eV}^{-1}\right)$ and $\mathbf{3} \quad(\eta=2.720 \mathrm{eV}, \quad \sigma=$ $0.368 \mathrm{eV}^{-1}$ ) compound 4 has a lower hardness value $(1.654 \mathrm{eV})$ and a higher value of softness $\left(0.604 \mathrm{eV}^{-1}\right)$.

$\Delta \mathrm{N}$ is defined as an amount of charge transfer between the molecules and the mild steel surface. If $\Delta \mathrm{N}$ has positive value then molecules have the ability to receive electrons, while a negative value of $\Delta \mathrm{N}$ show that the molecules have the ability to donate electron. ${ }^{41}$ In our case, all compounds have a positive value of $\Delta \mathrm{N}$ suggesting that the investigated molecules possess charge transfer abilities towards mild steel.

Compounds 1 and 4 that contain electron-donating groups $\left(-\mathrm{OCH}_{3},-\mathrm{NHCOCH}_{3}\right)$ exhibit better inhibitory efficiency than compounds $\mathbf{2}$ and $\mathbf{3}$ that contain electron-withdrawing groups $\left(-\mathrm{NO}_{2}\right.$, alkenyl chain) that is in correlation with the previously published results.

\section{$3.5{ }^{1} \mathrm{H}$ and ${ }^{13} \mathrm{C}$ NMR spectra}

The combination of experimental and theoretical studies could be a powerful and helpful tool for interpretation and prediction of molecular structures. Both ${ }^{1} \mathrm{H}$ and ${ }^{13} \mathrm{C}$ NMR spectra of selected compounds were previously recorded in DMSO, and all the ${ }^{1} \mathrm{H}$ NMR and ${ }^{13} \mathrm{C}$ NMR chemical shifts signals were assigned to the corresponding protons and carbons. In order to confirm these assignments, the ${ }^{1} \mathrm{H}$ and ${ }^{13} \mathrm{C}$ NMR spectra of the mentioned compounds were calculated using the GIAO method in DMSO with the CPCM solvation model at the B3LYP/6-311+G(d,p) level of theory. The experimental and calculated ${ }^{1} \mathrm{H}$ and ${ }^{13} \mathrm{C}$ NMR chemical shifts for compound $\mathbf{1}$ are presented in Table 5. For other compounds (2-4) see Supplementary Information. The atom positions were numbered as in the figure in Table 5. The isotropic chemical shifts are calculated with respect to tetramethylsilane (TMS) as standard. Calculated ${ }^{1} \mathrm{H}$ and ${ }^{13} \mathrm{C}$ isotropic chemical shifts were scaled with a single

Table 4. The quantum descriptors of compounds 1, 2, 3 and 4 calculated using DFT at B3LYP/6-311+G (d, p).

\begin{tabular}{cccccccccc}
\hline Parameter & $\mathrm{E}_{\text {homo }}(\mathrm{eV})$ & $\mathrm{E}_{\text {lumo }}(\mathrm{eV})$ & $\Delta \mathrm{E}(\mathrm{eV})$ & $\mathrm{A}(\mathrm{eV})$ & $\mathrm{I}(\mathrm{eV})$ & $\chi(\mathrm{eV})$ & $\eta(\mathrm{eV})$ & $\sigma\left(\mathrm{eV}^{-1}\right)$ & $\Delta \mathrm{N}$ \\
\hline 1 & -5.900 & -2.514 & 3.386 & 2.514 & 5.900 & 4.207 & 1.693 & 0.591 & 0.825 \\
2 & -5.961 & -2.332 & 3.629 & 2.332 & 5.961 & 4.146 & 1.814 & 0.551 & 0.786 \\
3 & -6.096 & -0.657 & 5.439 & 0.657 & 6.096 & 3.376 & 2.720 & 0.368 & 0.666 \\
4 & -6.237 & -2.928 & 3.309 & 2.928 & 6.237 & 4.582 & 1.654 & 0.604 & 0.731 \\
\hline
\end{tabular}


Table 5. Theoretical and experimental ${ }^{1} \mathrm{H}$ and ${ }^{13} \mathrm{C}$ isotropic chemical shifts for compound $\mathbf{1}$.

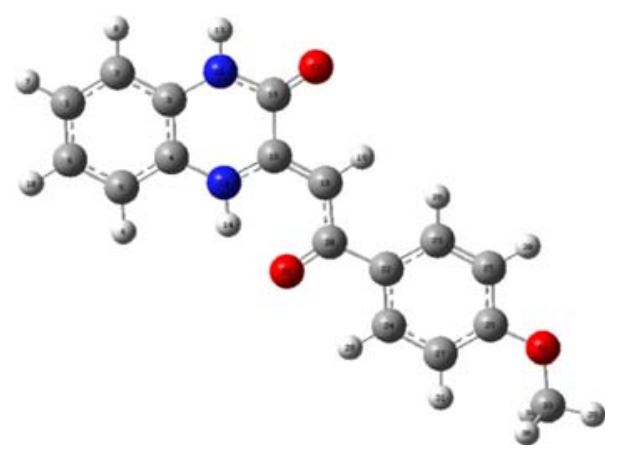

\begin{tabular}{lccccc}
\hline Atom & $\begin{array}{c}\text { Experimental } \\
\text { NMR }\end{array}$ & $\begin{array}{c}\text { Theoretical-scaled chemical } \\
\text { shifts }(\mathrm{ppm})\end{array}$ & Atom & $\begin{array}{c}\text { Experimental }{ }^{1} \mathrm{H} \\
\text { NMR }\end{array}$ & $\begin{array}{c}\text { Theoretical-scaled chemical } \\
\text { shifts (ppm) }\end{array}$ \\
\hline C1 & 115.6 & 123.8 & $\mathrm{H} 7$ & 7.05 & 8.4 \\
C2 & 114.2 & 114.9 & $\mathrm{H} 8$ & 7.05 & 8.4 \\
C3 & 129.4 & 125.0 & $\mathrm{H} 9$ & 7.05 & 8.1 \\
C4 & 116.4 & 126.1 & $\mathrm{H} 10$ & 7.05 & 8.4 \\
C5 & 114.2 & 114.4 & $\mathrm{H} 12$ & 13.57 & 8.9 \\
C6 & 115.6 & 123.2 & $\mathrm{H} 14$ & 11.96 & 7.9 \\
C15 & 145.2 & 142.9 & $\mathrm{H} 20$ & 6.76 & 9.1 \\
C16 & 156.1 & 154.0 & $\mathrm{H} 26$ & 7.94 & 8.1 \\
C18 & 89.2 & 89.3 & $\mathrm{H} 28$ & 7.94 & 8.1 \\
C19 & 188 & 184.6 & $\mathrm{H} 30$ & 7.05 & 4.8 \\
C22 & 131.6 & 130.5 & $\mathrm{H} 31$ & 7.42 & 4.5 \\
C23 & 124.5 & 128.6 & $\mathrm{H} 34$ & 3.82 & \\
C24 & 126.7 & 129.4 & $\mathrm{H} 35$ & 3.82 & \\
C25 & 123.9 & 115.7 & $\mathrm{H} 36$ & 3.82 & \\
C27 & 116.4 & 108.9 & & & \\
C29 & 162.6 & 162.3 & & & \\
C33 & 55.6 & 55.3 & & & \\
\hline
\end{tabular}

scaling factor of 1.1119 and 0.9409 , respectively. These scaling factors are calculated using the least squares method. Taking into account that the range of ${ }^{13} \mathrm{C}$ NMR chemical shifts for a typical organic molecule in most cases occur $>100 \mathrm{ppm}^{42}$ the accuracy confirms reliable of spectroscopic parameters. Chemical shifts for the carbon atoms that are part of the rings are $>100 \mathrm{ppm}$, as expected. The signal of aromatic carbon atoms was observed at 115.6, 114.2, $129.4,116.4,131.6,124.5$ and $126.7 \mathrm{ppm}$ which was calculated at 123.8, 114.9, 125.0, 126.1, 130.5, 128.6, 129.4 ppm.

Calculated ${ }^{13} \mathrm{C}$ isotropic chemical shifts match very well with experimental values with the correlation coefficients $\left(\mathrm{r}^{2}\right)$ of $0.9696(\mathbf{1}), 0.9910(\mathbf{2}), 0.9933(\mathbf{3})$ and 0.9528 (4). In the case of calculated ${ }^{1} \mathrm{H}$ isotropic chemical shifts there are good agreements but for $\mathrm{N}-\mathrm{H}$ chemical shifts a large deviation occurred. The agreement between the experimental and simulated $\mathrm{N}-\mathrm{H}$ chemical shifts is moderate, probably because of intra- or intermolecular interactions (hydrogen bond) that have not appeared in simulated structure.

\section{Conclusions}

Quinoxalinone and benzoxazinone derivatives, as a very important class of compounds, were explored by spectroscopy (UV-Vis, IR, Raman and NMR) and theoretical study (DFT calculations) for better understanding of their structure and chemical properties. Also, quantum chemical parameters were calculated in order to investigate the corrosion inhibition properties of these molecules. Presented results confirmed the applicability of the used method and basis set for quinoxaline- and benzoxazine-based compounds. The theoretical UV-Vis spectra and calculated HOMOLUMO orbitals are in agreement with experimental data. The positive value of $\Delta \mathrm{N}$ suggests that investigated molecules possess charge transfer abilities 
towards mild steel. Vibrational frequencies were calculated and compared with experimental values. A major source of some disagreement between the experimental and calculated band positions is the consequence of the fact that the calculations consider an isolated molecule and ignore intermolecular interactions. The vibrations of the analyzed samples are well identified in the collected Raman spectra within their characteristic regions and their calculated peak values coincide very well with the experimental values. Also, the values of the calculated chemical shifts for carbons notably are in excellent agreement with the experimental values. That is not the case, with chemical shifts for hydrogen atoms. There are some deviations for $\mathrm{N}-\mathrm{H}$ chemical shifts, probably because of the formation of hydrogen bond between two scaffolds (intermolecular interactions) or $\mathrm{N}-\mathrm{H}$ amine and carbonyl group from aryl or alkyl fragment (intramolecular interactions).

\section{Supplementary Information (SI)}

${ }^{1} \mathrm{H}$ NMR, ${ }^{13} \mathrm{C}$ NMR (experimental and theoretical), experimental UV-Vis and HOMO-LUMO data are submitted as Supplementary Information. Supplementary Information is available on www.ias.ac.in/chemsci.

\section{Acknowledgements}

The authors are grateful to the Ministry of Education, Science and Technological Development of the Republic of Serbia for financial support (Grant 172011). The authors would like to thank CESGA for allocation supercomputing facilities.

Conflict of interest The authors have declared no conflicts of interest.

\section{References}

1. Ramli Y, Moussaif A, Karrouchi K and Essassi E M 2014 Pharmacological profile of quinoxalinone $J$. Chem. 2014 ID 563406

2. Pereira J A, Pessoa A M, Cordeiro M N, Fernandes R, Prudêncio C, Noronha J P and Vieira M 2015 Quinoxaline, its derivatives and applications: A State of the Art review Eur. J. Med. Chem. 97664

3. Blattes E, Lockhart B, Lestage P, Schwendimann L, Gressens P, Fleury M B and Largeron M 2005 Novel 2-alkylamino-1,4-benzoxazine derivatives as potent neuroprotective agents: Structure-activity relationship studies J. Med. Chem. 481282

4. Ismail M, Amin K, Noaman E, Soliman D and Ammar Y 2010 New quinoxaline 1,4-di-N-oxides: Anticancer and hypoxia-selective therapeutic agents Eur. J. Med. Chem. 452733
5. Chitra S, Parameswari K, Vidhya M, Kalishwari M and Selvaraj A 2011 Evaluation of quinoxalines as corrosion inhibitors for mild steel in acid environment Int. J. Electrochem. Sci. 64593

6. Thomas K R J, Lin J T, Tao Y T and Chuen C H 2002 Quinoxalines incorporating triarylamines: potential electroluminescent materials with tunable emission characteristics Chem. Mater. 142796

7. Obi-Egbedi N O, Obot I B and El-Khaiary M I 2011 Quantum chemical investigation and statistical analysis of the relationship between corrosion inhibition efficiency and molecular structure of xanthene and its derivatives on mild steel in sulphuric acid J. Mol. Struct. 100286

8. Zarrouk A, Zarrok H, Salghi R, Hammouti B, Al-Deyab S S, Touzani R, Bouachrine M, Warad I and Hadda T B 2012 A Theoretical investigation on the corrosion inhibition of copper by quinoxaline derivatives in nitric acid solution Int. J. Electrochem. Sci. 76353

9. El-Hajjaji F, Zerga B, Sfaira M, Taleb M, Ebn Touhami M, Hammouti B, Al- Deyab S S, Benzeid H and Essassi E M 2014 Comparative study of novel N-substituted quinoxaline derivatives towards mild steel corrosion in hydrochloric acid: Part 1 J. Mater. Environ. Sci. 5255

10. Fu J J, Zang H S, Wang Y, Li S N, Chen T and Liu X D 2012 Experimental and theoretical study on the inhibition performances of quinoxaline and its derivatives for the corrosion of mild steel in hydrochloric acid Ind. Eng. Chem. Res. 516377

11. Zarrouk A, Hammouti B, Dafali A, Bouachrine M, Zarrok H, Boukhris S and Al-Deyab S S 2014 A theoretical study on the inhibition efficiencies of some quinoxalines as corrosion inhibitors of copper in nitric acid J. Saudi. Chem. Soc. 18450

12. Adardour K, Touir R, Ramli Y, Belakhmima R A, Ebn Touhami M, Mubengayi C K, Kafsaoui E H and Essassi E M 2013 Comparative inhibition study of mild steel corrosion in hydrochloric acid by new class synthesised quinoxaline derivatives: Part I Res. Chem. Intermed. 391843

13. Petronijević J, Bugarčić Z, Bogdanović G A, Stefanović S and Janković N 2017 An enolate ion as a synthon in biocatalytic synthesis of 3,4-dihydro-2(1H)quinoxalinones and 3,4-dihydro-1,4-benzoxazin-2ones: lemon juice as an alternative to hazardous solvents and catalysts Green Chem. 19707

14. Ayaza M, Dietricha J and Hulme C 2011 A novel route to synthesize libraries of quinoxalines via Petasis methodology in two synthetic operations Tetrahedron Lett. 524821

15. Palafox M A and Rastogi V K 2011 Vibrational spectra, tautomerism and thermodynamics of anticarcinogenic drug: 5-Fluorouracil Spectrochim. Acta A Mol. Biomol. Spectrosc. 79970

16. Devlin F J, Finley J W, Stephens P J and Frisch M J $1995 \mathrm{Ab}$ initio calculation of vibrational absorption and circular dichroism spectra using density functional force fields: A comparison of local, nonlocal, and hybrid density functionals J. Phys. Chem. 9916883

17. Seminario J M 1995 In Modern Density Functional Theory: A Tool for Chemistry P Politzer (Ed.) (Amsterdam: Elsevier) p. 49 
18. Becke A D 1992 Density-functional thermochemistry. II. The effect of the Perdew-Wang generalized-gradient correlation correction J. Chem. Phys. 97 9173; and 1993 Density-functional thermochemistry. III. The role of exact exchange J. Chem. Phys. 985648

19. Lee C, Yang W and Parr R G 1988 Development of the Colle-Salvetti correlation-energy formula into a functional of the electron density Phys. Rev. B 37785

20. Krishnan R, Binkley J S, Seeger R and Pople J A 1980 Self-consistent molecular orbital methods. XX. A basis set for correlated wave functions J. Chem. Phys. 72650

21. Gaussian 09, Revision C.01, Frisch M J, Trucks G W, Schlegel H B, Scuseria G E, Robb M A, Cheeseman J R, Scalmani G, Barone V, Mennucci B, Petersson G A, Nakatsuji H, Caricato M, Li X, Hratchian H P, Izmaylov A F, Bloino J, Zheng G, Sonnenberg J L, Hada M, Ehara M, Toyota K, Fukuda R, Hasegawa J, Ishida M, Nakajima T, Honda Y, Kitao O, Nakai H, Vreven T, Montgomery J A, Peralta J E, Ogliaro F, Bearpark M, Heyd J J, Brothers E, Kudin K N, Staroverov V N, Keith T, Kobayashi R, Normand J, Raghavachari K, Rendell A, Burant J C, Iyengar S S, Tomasi J, Cossi M, Rega N, Millam J M, Klene M, Knox J E, Cross J B, Bakken V, Adamo C, Jaramillo J, Gomperts R, Stratmann R E, Yazyev O, Austin A J, Cammi R, Pomelli C, Ochterski J W, Martin R L, Morokuma K, Zakrzewski V G, Voth G A, Salvador P, Dannenberg J J, Dapprich S, Daniels A D, Farkas O, Foresman J B, Ortiz J V, Cioslowski J and Fox D J 2010 Gaussian, Inc., Wallingford CT

22. Andersson M P and Uvdal P 2005 New scale factors for harmonic vibrational frequencies using the B3LYP density functional method with the triple-zeta basis set 6-311+G(d,p) J. Phys. Chem. A 1092937

23. Wolinski K, Hilton J F and Pulay P 1990 Efficient implementation of the Gauge-Independent Atomic Orbital method for NMR chemical shift calculations $J$. Am. Chem. Soc. 1128251

24. Silverstein R M, Webster F X and Kiemle D J 2005 In Spectrometric Identification of Organic Compounds (London: John Willey) p. 72

25. Babu N R, Subashchandrabose S, Padusha M S A, Saleem H, Manivannan V and Erdogdu Y 2014 Synthesis and structural characterization of $(\mathrm{E})-\mathrm{N}^{\prime}-((\mathrm{Pyr}-$ idin-2-yl) methylene) benzohydrazide by X-ray diffraction, FT-IR, FT-Raman and DFT methods $J$. Mol. Struct. 107284

26. Weinhold F 2005 In Valency and bonding: a natural bond orbital donor-acceptor perspective C R Landis (Ed.) (Location: Cambridge University Press) p. 367

27. Krishnakumar V and Muthunatesan S 2007 DFT studies of the structure and vibrational assignments of 4-hydroxy quinazoline and 2-hydroxy benzimidazole Spectrochim. Acta Part A 661082

28. Krishnakumar V, Mathammal $\mathrm{R}$ and Muthunatesan $\mathrm{S}$ 2008 Structures and vibrational frequencies of 2-naphthoic acid and 6-bromo-2-naphthoic acid based on density functional theory calculations Spectrochim. Acta Part A $\mathbf{7 0} 201$
29. Schrader B (Ed.) 1995 In Infrared and Raman Spectroscopy: Methods and Applications (Germany: WileyVCH Verlag $\mathrm{GmbH}$ ) p. 191

30. Tomasi J, Mennucci B and Cammi R 2005 Quantum mechanical continuum solvation models Chem. Rev. 1052999

31. Umoren S A, Ogbobe O, Igwe I O and Ebenso E E 2008 Inhibition of mild steel corrosion in acidic medium using synthetic and naturally occurring polymers and synergistic halide additives Corros. Sci. 50 1998

32. Gupta R K, Malviya M, Verma C and Quraishi M A 2017 Aminoazobenzene and diaminoazobenzene functionalized graphene oxides as novel class of corrosion inhibitors for mild steel: Experimental and DFT studies Mater. Chem. Phys. 198360

33. Verma C, Ebenso E E and Quraishi M A 2017 Ionic liquids as green and sustainable corrosion inhibitors for metals and alloys: An overview J. Mol. Liq. 233403

34. Yadav M, Sinha R R, Kumar S and Sarkar T K 2015 Corrosion inhibition effect of spiropyrimidinethiones on mild steel in $15 \% \mathrm{HCl}$ solution insight from: electrochemical and quantum studies RSC Adv. 570832

35. Harvey T G, Hardin S G, Hughes A E, Muster T H, White P A, Markley T A, Corrigan P A, Mardel J, Garcia S J, Mol J M C and Glenn A M 2011 The effect of inhibitor structure on the corrosion of AA2024 and AA7075 Corros. Sci. 532184

36. Sagdinc S G and Kara Y S 2014 Theoretical elucidation on corrosion inhibition efficiency of 11-cyano undecanoic acid phenylamide derivatives: DFT study Prot. Metal. Phys. Chem. Surf. 50111

37. Bouoidina A, Hajjaji E F, Abdellaoui A, Rais Z, Filali Baba M, Chaouch M, Karzazi O, Lahkimi A and Taleb M 2017 Theoretical and experimental study of the corrosion inhibition of mild steel in acid medium using some surfactants of the essential oil of FoeniculumVulgare bulb J. Mater. Environ. Sci. 81328

38. Awad M K 2013 Quantum chemical studies and molecular modeling of the effect of polyethylene glycol as corrosion inhibitors of an aluminum surface $C a n$. J. Chem. 91283

39. Costa R A, Oliveira K M T, Costa E V and Pinheiro M L B 2017 Vibrational, structural and electronic properties investigation by DFT calculations and molecular docking studies with DNA topoisomerase II of strychnobrasiline type alkaloids: a theoretical approach for potentially bioactive molecules J. Mol. Struct. 1145 254

40. Obot I B and Gasem Z M 2014 Theoretical evaluation of corrosion inhibition performance of some pyrazine derivatives Corros. Sci. 83359

41. Kovacevic N and Kokalj A 2011 DFT study of interaction of azoles with $\mathrm{Cu}$ (III) and $\mathrm{Al}$ (III) Surfaces: role of azole nitrogen atoms and dipole-dipole interactions J. Phys. Chem. C 11524189

42. Kalinowski H O, Berger S and Braun S 1988 Carbon13 NMR Spectroscopy (Chichester: John Wiley \& Sons) p. 512 